\title{
Comparison of neonatal reference intervals for 23 biochemical analytes in the cord blood-A single center study in South Korea
}

\author{
Seong Jin Choi ${ }^{1, *}$, Saejin Lee ${ }^{2, *}$, Byoungkook Lee ${ }^{3}$, Jae Yun Jang ${ }^{2}$, Jooyoung Cho ${ }^{2}$, \\ Young $\mathrm{Uh}^{2}$
}

Departments of ${ }^{1}$ Obstetrics and Gynecology, ${ }^{2}$ Laboratory Medicine, and ${ }^{3}$ Pediatrics, Yonsei University Wonju College of Medicine, Wonju, Korea.E-mail:u931018@yonsei.ac.kr

Received: 19th May 2018, Revised: 7th September 2018, 19th October 2018,

24th December 2018, Accepted: 4th January 2019

*Seong Jin Choi and Saejin Lee contributed equally to this work as first authors

SUMMARY: Choi SJ, Lee S, Lee B, Jang JY, Cho J, Uh Y. Comparison of neonatal reference intervals for 23 biochemical analytes in the cord blood-A single center study in South Korea. Turk J Pediatr 2019; 61: 337-344.

Reference intervals for laboratory tests are important in the diagnosis and treatment of disease. However, due to difficulty in recruiting sufficient numbers of reference subjects, studies regarding reference intervals for biochemical analytes in neonates is lacking. The aim of this study was to compare and validate the reference intervals for 23 biochemical analytes in the cord blood of neonates. From August to December 2017, 79 consecutive neonates born at the Wonju Severance Christian Hospital (Wonju, Korea) with C-reactive protein concentration less than $0.05 \mathrm{mg} / \mathrm{dL}$ were included in this study. All of 23 biochemical analytes were measured by the cobas 8000 c702 (Roche Diagnostics, Switzerland). Mean \pm 2 standard deviations (SD) were calculated if the values were normally distributed, and median and the range of 2.5-97.5 percentile were described when the values were not normally distributed. We compared the neonatal reference intervals for 23 biochemical analytes. Alkaline phosphatase and gamma glutamyl transferase showed significant differences according to sex, and direct bilirubin revealed significant differences depending on the delivery mode. These compared reference intervals of 23 biochemical analytes will be useful for clinical decision-making in the management of neonates.

Key words: biochemical, cord blood, neonates, reference interval.

Reference intervals are one of the most widely used clinical decision-making tools that help physicians differentiate between healthy and diseased populations. ${ }^{1}$ Moreover, it has been emphasized that neonatal reference intervals play a significant role in the optimal management of the postnatal adaptation phase. ${ }^{2}$ Current guidelines define a reference interval as the interval between two values within which $95 \%$ of the results from healthy individuals would fall; usually between the 2.5th and 97.5th percentiles of test results for a healthy population. ${ }^{3}$ The reference intervals of laboratory parameters vary according to the demographic characteristics such as ethnicity, sex, age, and the time of sample collection..$^{4-7}$ Therefore, it is recommended that laboratories establish their own reference intervals from the local population or validate the use of those obtained from a different setting. However, it requires a lot of labor, time and cost for application in clinical conditions. ${ }^{8}$ Especially, it is more difficult in neonates due to the limitation of obtaining a sufficient number of reference individuals. ${ }^{9,10}$ For this reason, to date, only a few studies have been conducted on neonatal reference intervals, and there are no acceptable reference intervals for 
many laboratory parameters in neonates.

Thus, the aim of this study was to compare the reference intervals in neonates for 23 biochemical analytes using the cord blood in our hospital.

\section{Material and Methods}

\section{Study population}

Twenty-eight preterm (26 to 31 weeks' gestation: 3 neonates, 32 to 36 weeks' gestation: 25 neonates) and 51 term (37 to 42 weeks' gestation) neonates born at Wonju Severance Christian Hospital between August and October 2017 were enrolled prospectively. The study protocol was approved by the Institutional Review Board of Wonju Severance Christian Hospital (approval no. CR317056). We obtained parental written informed consent prior to enrollment.

\section{Sample collection and Laboratory procedure}

Each cord blood sample (up to $10 \mathrm{~mL}$ ) was collected in two serum separation tubes (Becton Dickinson, Franklin Lakes, New Jersey, USA) from the umbilical vein immediate after delivery by sterile puncture. The cord blood samples were immediately transported to the laboratory and centrifuged. Separated sera were transferred to cryovial tubes (SPL Life Sciences, Pocheon, Korea), and stored at $-80^{\circ} \mathrm{C}$ until tested. Clinical data included delivery mode, spontaneous rupture of the membranes, gestational weeks, birth weight, and multiple pregnancies. Prior to analysis, all samples were thawed at room temperature, then analyzed with the cobas 8000 c702 (Roche Diagnostics, Basel, Switzerland) according to the manufacturer's instructions. The 23 biochemical analytes were as follows: total protein, albumin, blood urea nitrogen (BUN), creatinine, aspartate transaminase (AST), alanine transaminase (ALT), alkaline phosphatase (ALP), gamma-glutamyl transferase (GGT), creatine kinase, lactate dehydrogenase (LDH), total cholesterol, high density lipoprotein cholesterol (HDL-C), low density lipoprotein cholesterol (LDL-C), triglyceride, total bilirubin, direct bilirubin, calcium, inorganic phosphate, magnesium, iron, unsaturated iron binding capacity, uric acid, and glucose. C-reactive protein (CRP) was also tested with the cobas 8000 c702 to assess neonatal health status.

\section{Statistical analysis}

To determine the reference subjects, extreme observations were excluded. If the absolute difference between the largest observation and the second largest was equal to or greater than one-third of the range of all observations including the extreme values, the extreme values were regarded as outliers and were excluded. ${ }^{11}$ The same criterion was applied to the minimum observation. Then, the Kolmogorov-Smirnov test was used to confirm normality. Distribution of a variable was determined with normality when the $p$ value of the Kolmogorov-Smirnov test was larger than 0.05 . If the values were normally distributed, the parametric method (mean $\pm 2 \mathrm{SD}$ ) was used to compare the reference interval while the non-parametric method (median and the range of 2.5-97.5 percentile) was used when the values were not normally distributed. ${ }^{3}$

The study population was divided into three subgroups, namely, delivery mode, sex, and gestational week of newborns. The mean of each subgroup was calculated and compared by an independent t-test when data showed normality in the distribution, while the Mann-Whitney $U$ test was used when data were not normally distributed. A p value < 0.05 was considered statistically significant. If the difference between the means of each subgroup exceeded $25 \%$ of the total range of all observations, then reference intervals were required for further evaluation or validation for each subgroup respectively. ${ }^{12-14}$ Statistical analyses were performed using MedCalc for Windows, version 14.8.1 (MedCalc Software, Ostend, Belgium) and IBM SPSS Statistics version 23 (IBM Corporation, Armonk, New York, USA).

\section{Results}

All of the 79 neonates had CRP concentrations less than $0.02 \mathrm{mg} / \mathrm{dL}$ except for 3 neonates (one term baby, $0.04 \mathrm{mg} / \mathrm{dL}$, and two preterm babies, $0.03 \mathrm{mg} / \mathrm{dL}$ ). Table I shows the characteristics of two subgroups, vaginal delivery $(n=24)$ 
Table I. The Demographic Characteristics of the Study Population According to Mode of Delivery.

\begin{tabular}{lccc}
\hline Characteristics & $\begin{array}{c}\text { Vaginal delivery } \\
(\mathrm{n}=24)\end{array}$ & $\begin{array}{c}\text { Cesarean section } \\
(\mathrm{n}=55)\end{array}$ & $P$ value \\
\hline Sex (male), $\mathrm{n}(\%)$ & $11(45.8)$ & $31(57.1)$ & 0.536 \\
Birth weight (kg), mean $\pm \mathrm{SD}$ & $2.91 \pm 0.5$ & $2.76 \pm 0.7$ & 0.382 \\
Gestational age (weeks), mean $\pm \mathrm{SD}$ & $37.5 \pm 2.6$ & $36.3 \pm 2.6$ & 0.066 \\
Maternal age (years), mean $\pm \mathrm{SD}$ & $31.5 \pm 6.3$ & $34.0 \pm 4.8$ & 0.056 \\
Rupture of amniotic membrane, $\mathrm{n}(\%)$ & $22(91.7)$ & $12(21.8)$ & $<0.001$ \\
\hline
\end{tabular}

$\mathrm{SD}$, standard deviation.

and Cesarean section $(\mathrm{n}=55)$. Only the rupture of the amniotic membrane showed statistically significant higher proportions in the vaginal delivery group, whereas sex, birth weight, gestational age, and maternal age did not show any significant differences between the vaginal delivery and Cesarean section groups.

Total protein, albumin, BUN, total cholesterol, HDL-C, total bilirubin, direct bilirubin, iron, uric acid, and glucose showed normal distributions and were analyzed by the parametric statistical method. The other parameters showing non-normal distributions were analyzed by non-parametric statistical methods. Among the 23 biochemical analytes, ALP and GGT showed significant differences depending on sex, and direct bilirubin revealed significant differences depending on the delivery mode (Table II). However, the subgroup-specific reference intervals were not established because the differences were less than $25 \%$ of the total range of all observations.

Table III shows the proposed reference intervals for the 23 biochemical analytes in the cord blood of Korean neonates.

\section{Discussion}

Determining reference intervals for neonates, infants and children is a challenging assignment since the physiological characteristics are changing continuously as they grow. ${ }^{15}$ Especially in newborns, striking changes occur in the blood during the first few hours and days after birth. ${ }^{16}$ In addition, since most of the studies were conducted on hospitalized subjects rather than normal neonates, ${ }^{8}$ the evidence for determining reference intervals for neonates are scarce. Therefore, it is important to establish the reference intervals for normal neonates.

Given the substantial physiological changes in neonates, the time of blood sampling is crucial for determining the appropriate reference intervals. Therefore, a standardized method for blood sampling is required and immediate blood sampling from the umbilical cord at delivery provides uniform sampling conditions. In addition, this method allows avoidance of additional venipuncture and inclusion of healthy newborns as well as hospitalized neonates.

Compared with neonatal reference intervals for 21 biochemical parameters reported by Perkins et al. ${ }^{17}$, there were no notable differences except for iron, but our analyzed ranges were slightly wider in some parameters. This might result from the different ethnicity and relatively small number of neonates in our study. For iron, analyzed range in our study was within neonatal reference interval, but the upper limit was lower than reference range. In this study, of the 79 neonates recruited, 28 (35.4) were preterm (gestational age less than 37 weeks). Previous studies reported that preterm birth is associated with body iron status. ${ }^{18}$ This is one of our limitation, so further evaluation with more neonates covering variable gestational ages are needed.

In comparison to the reference intervals for 1 -year-old Korean children, ${ }^{19}$ the low values of total protein and albumin in the neonates were similar to the previous study, showing a gradual increase in total serum proteins and albumin with age. ${ }^{20}$ In contrast, GGT showed far higher levels in neonates than in 1-year- 
Table II. Summary of Descriptive Statistics for 23 Biochemical Analytes in the Total Population and Subgroups According to Sex, Delivery Type, and Gestational Weeks in This Study.

\begin{tabular}{|c|c|c|c|c|c|}
\hline \multirow[t]{2}{*}{ Analytes, unit } & \multirow[t]{2}{*}{ Total } & \multirow{2}{*}{$\begin{array}{c}\mathrm{K}-\mathrm{S} \\
p \text { value }\end{array}$} & \multicolumn{2}{|c|}{ Sex } & \multirow[t]{2}{*}{$p$ value* } \\
\hline & & & Male & Female & \\
\hline T-Pro†, g/dL & $5.2 \pm 0.6$ & 0.189 & $5.2 \pm 0.6$ & $5.3 \pm 0.7$ & 0.511 \\
\hline Alb $\dagger, g / d L$ & $3.3 \pm 0.4$ & 0.200 & $3.3 \pm 0.4$ & $3.3 \pm 0.4$ & 0.810 \\
\hline $\mathrm{BUN} \dagger, \mathrm{mg} / \mathrm{dL}$ & $9 \pm 3$ & 0.094 & $9 \pm 2$ & $8 \pm 2$ & 0.083 \\
\hline $\mathrm{Cr}+, \mathrm{mg} / \mathrm{dL}$ & $\begin{array}{c}0.6 \\
(0.2-0.9)\end{array}$ & 0.037 & $\begin{array}{c}0.6 \\
(0.3-0.9)\end{array}$ & $\begin{array}{c}0.6 \\
(0.2-0.8)\end{array}$ & 0.133 \\
\hline AST,$+ U / L$ & $\begin{array}{c}27.0 \\
(16-73)\end{array}$ & $<0.001$ & $\begin{array}{c}28.0 \\
(12-72)\end{array}$ & $\begin{array}{c}26.0 \\
(16-72)\end{array}$ & 0.838 \\
\hline ALT,$+ U / L$ & $\begin{array}{c}7.0 \\
(3-20)\end{array}$ & $<0.001$ & $\begin{array}{c}6.0 \\
(3-20)\end{array}$ & $\begin{array}{c}8.0 \\
(3-24)\end{array}$ & 0.131 \\
\hline ALP+ + U/L & $\begin{array}{c}155.0 \\
(91-269)\end{array}$ & 0.003 & $\begin{array}{c}146.0 \\
(91-269)\end{array}$ & $\begin{array}{c}164.0 \\
(94-270)\end{array}$ & 0.006 \\
\hline GGT,$+ U / L$ & $\begin{array}{c}141.0 \\
(29-502)\end{array}$ & $<0.001$ & $\begin{array}{c}129.0 \\
(24-475)\end{array}$ & $\begin{array}{c}163.0 \\
(29-592)\end{array}$ & 0.037 \\
\hline $\mathrm{CK}_{+}^{+}, \mathrm{U} / \mathrm{L}$ & $\begin{array}{c}200.0 \\
(48-505)\end{array}$ & $<0.001$ & $\begin{array}{c}187.0 \\
(38-538)\end{array}$ & $\begin{array}{c}203.0 \\
(85-439)\end{array}$ & 0.260 \\
\hline LDH+, U/L & $\begin{array}{c}342.0 \\
(200-926)\end{array}$ & $<0.001$ & $\begin{array}{c}325.5 \\
(194-641)\end{array}$ & $\begin{array}{c}356.0 \\
(223-631)\end{array}$ & 0.096 \\
\hline T-Chol $\dagger, \mathrm{g} / \mathrm{dL}$ & $54 \pm 36$ & 0.074 & $58 \pm 35$ & $48 \pm 37$ & 0.234 \\
\hline $\mathrm{HDL}-\mathrm{C} \dagger, \mathrm{mg} / \mathrm{dL}$ & $34 \pm 11$ & 0.200 & $32 \pm 11$ & $36 \pm 11$ & 0.181 \\
\hline LDL-C,$+ \mathrm{mg} / \mathrm{dL}$ & $\begin{array}{c}25.0 \\
(4-59)\end{array}$ & $<0.001$ & $\begin{array}{c}25.0 \\
(4-62)\end{array}$ & $\begin{array}{c}26.0 \\
(4-59)\end{array}$ & 0.468 \\
\hline TG+, mg/dL & $\begin{array}{c}22.0 \\
(10-79)\end{array}$ & $<0.001$ & $\begin{array}{c}22.0 \\
(10-79)\end{array}$ & $\begin{array}{c}22.0 \\
(9-83)\end{array}$ & 0.644 \\
\hline T-Bil†, mg/dL & $1.7 \pm 0.4$ & 0.200 & $1.7 \pm 0.4$ & $1.7 \pm 0.4$ & 0.872 \\
\hline D-Bil†, mg/dL & $0.5 \pm 0.2$ & 0.200 & $0.5 \pm 0.2$ & $0.5 \pm 0.2$ & 0.544 \\
\hline $\mathrm{Ca}+, \mathrm{mg} / \mathrm{dL}$ & $\begin{array}{c}9.7 \\
(4.8-11.2)\end{array}$ & $<0.001$ & $\begin{array}{c}9.7 \\
(4.6-11.2)\end{array}$ & $\begin{array}{c}9.7 \\
(6.0-11.2)\end{array}$ & 0.926 \\
\hline $\mathrm{P}+, \mathrm{mg} / \mathrm{dL}$ & $\begin{array}{c}5.7 \\
(4.2-26.8)\end{array}$ & $<0.001$ & $\begin{array}{c}5.7 \\
(4.6-26.3)\end{array}$ & $\begin{array}{c}5.8 \\
(4.0-31.5)\end{array}$ & 0.746 \\
\hline $\mathrm{Mg}_{+}^{\ddagger}, \mathrm{mg} / \mathrm{dL}$ & $\begin{array}{c}1.9 \\
(1.6-3.6)\end{array}$ & $<0.001$ & $\begin{array}{c}1.9 \\
(1.7-3.5)\end{array}$ & $\begin{array}{c}2.0 \\
(1.5-3.7)\end{array}$ & 0.362 \\
\hline $\mathrm{Fe} \dagger, \mu \mathrm{g} / \mathrm{dL}$ & $172 \pm 48$ & 0.200 & $177 \pm 50$ & $167 \pm 45$ & 0.359 \\
\hline $\mathrm{UIBC}+, \mu \mathrm{g} / \mathrm{dL}$ & $\begin{array}{c}55.0 \\
(13-319)\end{array}$ & $<0.001$ & $\begin{array}{c}47.0 \\
(11-311)\end{array}$ & $\begin{array}{c}59.0 \\
(13-272)\end{array}$ & 0.336 \\
\hline $\mathrm{UA} \dagger, \mathrm{mg} / \mathrm{dL}$ & $4.8 \pm 1.4$ & 0.200 & $5.0 \pm 1.6$ & $4.5 \pm 1.1$ & 0.069 \\
\hline Glu†, mg/dL & $69 \pm 23$ & 0.184 & $67 \pm 23$ & $71 \pm 23$ & 0.469 \\
\hline
\end{tabular}

K-S, Kolmogorov-Smirnov test; NSVD, normal spontaneous vaginal delivery; C/S, Cesarean section; T-Pro, total protein; Alb, albumin; BUN, blood urea nitrogen; Cr, creatinine; AST, aspartate transaminase; ALT, alanine transaminase; ALP, alkaline phosphatase; GGT, gamma-glutamyl transferase; CK, creatine kinase; LDH, lactate dehydrogenase; T-Chol, total cholesterol; HDL-C, high density lipoprotein cholesterol; LDL-C, low density lipoprotein cholesterol; TG, triglyceride; T-Bil, total bilirubin; D-Bil, direct bilirubin; Ca, calcium; P, inorganic phosphate; $\mathrm{Mg}$, magnesium; Fe, iron; UIBC, unsaturated iron binding capacity; UA, uric acid; Glu, glucose.

*A $p$ value $<0.05$ indicated a statistically significant difference between the two groups.

$\uparrow$ Normally distributed data were expressed as mean $\pm 2 \mathrm{SD}$ and compared by an independent t-test.

$\$$ Variables with values not normally distributed were expressed as median and the range of $2.5-97.5$ percentiles and compared by the

Mann-Whitney U test. 
Table II (Continue). Summary of Descriptive Statistics for 23 Biochemical Analytes in the Total Population and Subgroups According to Sex, Delivery Type, and Gestational Weeks in This Study.

\begin{tabular}{|c|c|c|c|c|c|}
\hline \multicolumn{2}{|c|}{ Delivery mode } & \multirow[t]{2}{*}{$p$ value* } & \multicolumn{2}{|c|}{ Gestational week } & \multirow[t]{2}{*}{$p$ value* } \\
\hline NSVD & $\mathrm{C} / \mathrm{S}$ & & Preterm & Term & \\
\hline $5.2 \pm 0.7$ & $5.2 \pm 0.6$ & 0.598 & $5.2 \pm 0.8$ & $5.2 \pm 0.6$ & 0.761 \\
\hline $3.3 \pm 0.5$ & $3.3 \pm 0.3$ & 0.989 & $3.3 \pm 0.3$ & $3.3 \pm 0.4$ & 0.735 \\
\hline $9 \pm 3$ & $8 \pm 2$ & 0.852 & $9 \pm 4$ & $9 \pm 2$ & 0.966 \\
\hline $\begin{array}{c}0.6 \\
(0.2-0.8)\end{array}$ & $\begin{array}{c}0.6 \\
(0.2-0.9)\end{array}$ & 0.880 & $\begin{array}{c}0.6 \\
(0.2-1.0)\end{array}$ & $\begin{array}{c}0.6 \\
(0.2-0.8)\end{array}$ & 0.604 \\
\hline $\begin{array}{c}35.0 \\
(16-73)\end{array}$ & $\begin{array}{c}27.0 \\
(13-57)\end{array}$ & 0.073 & $\begin{array}{c}27.5 \\
(16-72)\end{array}$ & $\begin{array}{c}27.0 \\
(16-73)\end{array}$ & 0.715 \\
\hline $\begin{array}{c}6.5 \\
(3-20)\end{array}$ & $\begin{array}{c}7.0 \\
(3-22)\end{array}$ & 0.881 & $\begin{array}{c}6.5 \\
(3-15)\end{array}$ & $\begin{array}{c}7.0 \\
(3-18)\end{array}$ & 0.589 \\
\hline $\begin{array}{c}147.5 \\
(114-270)\end{array}$ & $\begin{array}{c}159.0 \\
(91-240)\end{array}$ & 0.860 & $\begin{array}{c}164.0 \\
(92-269)\end{array}$ & $\begin{array}{c}150.0 \\
(91-252)\end{array}$ & 0.386 \\
\hline $\begin{array}{c}160.0 \\
(30-592)\end{array}$ & $\begin{array}{c}134.0 \\
(25-477)\end{array}$ & 0.069 & $\begin{array}{c}149.5 \\
(29-434)\end{array}$ & $\begin{array}{c}137.0 \\
(30-502)\end{array}$ & 0.442 \\
\hline $\begin{array}{c}169.5 \\
(70-344)\end{array}$ & $\begin{array}{c}207.0 \\
(41-479)\end{array}$ & 0.424 & $\begin{array}{c}167.5 \\
(37-382)\end{array}$ & $\begin{array}{c}214.0 \\
(73-540)\end{array}$ & 0.178 \\
\hline $\begin{array}{c}408.5 \\
(194-631)\end{array}$ & $\begin{array}{c}338.0 \\
(208-633)\end{array}$ & 0.181 & $\begin{array}{c}367.0 \\
(194-646)\end{array}$ & $\begin{array}{c}332.0 \\
(223-926)\end{array}$ & 0.465 \\
\hline $53 \pm 42$ & $54 \pm 33$ & 0.918 & $57 \pm 34$ & $52 \pm 37$ & 0.559 \\
\hline $34 \pm 11$ & $34 \pm 11$ & 0.842 & $55 \pm 36$ & $33 \pm 10$ & 0.183 \\
\hline $\begin{array}{c}23.0 \\
(12-59)\end{array}$ & $\begin{array}{c}26.0 \\
(4-60)\end{array}$ & 0.304 & $\begin{array}{c}27.0 \\
(4-50)\end{array}$ & $\begin{array}{c}25.0 \\
(12-62)\end{array}$ & 0.885 \\
\hline $\begin{array}{l}23.0 \\
(9-79)\end{array}$ & $\begin{array}{c}21.0 \\
(12-79)\end{array}$ & 0.802 & $\begin{array}{c}22.0 \\
(9-74)\end{array}$ & $\begin{array}{c}22.0 \\
(12-51)\end{array}$ & 0.817 \\
\hline $1.8 \pm 0.5$ & $1.6 \pm 0.4$ & 0.264 & $2.4 \pm 1.7$ & $1.7 \pm 0.4$ & 0.705 \\
\hline $0.4 \pm 0.2$ & $0.5 \pm 0.2$ & 0.030 & $1.3 \pm 0.5$ & $0.5 \pm 0.2$ & 0.717 \\
\hline $\begin{array}{c}9.7 \\
(4.6-10.8)\end{array}$ & $\begin{array}{c}9.7 \\
(6.0-11.2)\end{array}$ & 0.605 & $\begin{array}{c}9.8 \\
(7.3-10.6)\end{array}$ & $\begin{array}{c}9.7 \\
(4.8-10.8)\end{array}$ & 0.517 \\
\hline $\begin{array}{c}6.5 \\
(4.5-31.5)\end{array}$ & $\begin{array}{c}5.6 \\
(4.1-25.5)\end{array}$ & 0.084 & $\begin{array}{c}5.4 \\
(4.2-25.2)\end{array}$ & $\begin{array}{c}5.8 \\
(4.5-25.7)\end{array}$ & 0.854 \\
\hline $\begin{array}{c}1.9 \\
(1.5-3.7)\end{array}$ & $\begin{array}{c}1.9 \\
(1.7-3.2)\end{array}$ & 0.858 & $\begin{array}{c}1.9 \\
(1.6-3.2)\end{array}$ & $\begin{array}{c}1.9 \\
(1.7-3.6)\end{array}$ & 0.679 \\
\hline $166 \pm 38$ & $175 \pm 51$ & 0.442 & $176 \pm 54$ & $170 \pm 44$ & 0.640 \\
\hline $\begin{array}{c}64.5 \\
(15-154)\end{array}$ & $\begin{array}{c}46.0 \\
(12-301)\end{array}$ & 0.436 & $\begin{array}{c}53.5 \\
(11-272)\end{array}$ & $\begin{array}{c}56.0 \\
(14-266)\end{array}$ & 0.808 \\
\hline $4.3 \pm 1.2$ & $5.0 \pm 1.5$ & 0.071 & $4.8 \pm 1.5$ & $4.7 \pm 1.4$ & 0.917 \\
\hline $65 \pm 18$ & $70 \pm 25$ & 0.409 & $71 \pm 23$ & $67 \pm 23$ & 0.465 \\
\hline
\end{tabular}

K-S, Kolmogorov-Smirnov test; NSVD, normal spontaneous vaginal delivery; C/S, Cesarean section; T-Pro, total protein; Alb, albumin; BUN, blood urea nitrogen; Cr, creatinine; AST, aspartate transaminase; ALT, alanine transaminase; ALP, alkaline phosphatase; GGT, gamma-glutamyl transferase; CK, creatine kinase; LDH, lactate dehydrogenase; T-Chol, total cholesterol; HDL-C, high density lipoprotein cholesterol; LDL-C, low density lipoprotein cholesterol; TG, triglyceride; T-Bil, total bilirubin; D-Bil, direct bilirubin; Ca, calcium; P, inorganic phosphate; $\mathrm{Mg}$, magnesium; Fe, iron; UIBC, unsaturated iron binding capacity; UA, uric acid; Glu, glucose.

${ }^{*}$ A $p$ value $<0.05$ indicated a statistically significant difference between the two groups.

$\uparrow$ Normally distributed data were expressed as mean $\pm 2 \mathrm{SD}$ and compared by an independent t-test.

$\$$ Variables with values not normally distributed were expressed as median and the range of $2.5-97.5$ percentiles and compared by the

Mann-Whitney U test. 
Table III. Proposed Reference Intervals for the 23 Biochemical Analytes in the Cord Blood of 79 Neonates.

\begin{tabular}{|c|c|c|}
\hline Analytes, unit & Neonatal reference intervals & $\begin{array}{l}1 \text {-year-old } \\
\text { reference intervals }\end{array}$ \\
\hline T-Pro, g/dL & $4.0-6.4$ & $5.7-7.6$ \\
\hline Alb, g/dL & $2.5-4.1$ & $3.9-4.9$ \\
\hline $\mathrm{BUN}, \mathrm{mg} / \mathrm{dL}$ & $3-15$ & $5-19$ \\
\hline $\mathrm{Cr}, \mathrm{mg} / \mathrm{dL}$ & $0.2-0.9$ & $0.2-0.5$ \\
\hline AST, U/L & $16-73$ & $27-64$ \\
\hline ALT, U/L & $3-20$ & $11-45$ \\
\hline ALP, U/L & $91-269$ & $146-447$ \\
\hline GGT, U/L & $29-502$ & $4-16$ \\
\hline $\mathrm{CK}, \mathrm{U} / \mathrm{L}$ & $48-505$ & $\mathrm{~N} / \mathrm{A}$ \\
\hline LDH, U/L & $200-926$ & $\mathrm{~N} / \mathrm{A}$ \\
\hline T-Chol, mg/dL & $<126$ & $115-224$ \\
\hline HDL-C, mg/dL & $12-56$ & $26-71$ \\
\hline LDL-C, mg/dL & $4-59$ & $51-146$ \\
\hline $\mathrm{TG}, \mathrm{mg} / \mathrm{dL}$ & $10-79$ & $48-261$ \\
\hline T-Bil, mg/dL & $0.9-2.5$ & $0.2-0.9$ \\
\hline D-Bil, mg/dL & $0.1-0.9$ & $\mathrm{~N} / \mathrm{A}$ \\
\hline $\mathrm{Ca}, \mathrm{mg} / \mathrm{dL}$ & $4.8-11.2$ & $8.7-10.8$ \\
\hline $\mathrm{P}, \mathrm{mg} / \mathrm{dL}$ & $4.2-26.8$ & $4.4-6.6$ \\
\hline $\mathrm{Mg}, \mathrm{mg} / \mathrm{dL}$ & $1.6-3.6$ & $\mathrm{~N} / \mathrm{A}$ \\
\hline $\mathrm{Fe}, \mu \mathrm{g} / \mathrm{dL}$ & $76-268$ & $\mathrm{~N} / \mathrm{A}$ \\
\hline UIBC, $\mu \mathrm{g} / \mathrm{dL}$ & $13-319$ & $\mathrm{~N} / \mathrm{A}$ \\
\hline $\mathrm{UA}, \mathrm{mg} / \mathrm{dL}$ & $2.0-7.6$ & $2.1-5.2$ \\
\hline Glu, mg/dL & $23-115$ & $68-121$ \\
\hline
\end{tabular}

T-Pro, total protein; Alb, albumin; BUN, blood urea nitrogen; $\mathrm{Cr}$, creatinine; AST, aspartate transaminase; ALT, alanine transaminase; ALP, alkaline phosphatase; GGT, gamma-glutamyl transferase; CK, creatine kinase; NA, Not available; LDH, lactate dehydrogenase; T-Chol, total cholesterol; HDL-C, high density lipoprotein cholesterol; LDL-C, low density lipoprotein cholesterol; TG, triglyceride; T-Bil, total bilirubin; D-Bil, direct bilirubin; Ca, calcium; P, inorganic phosphate; $\mathrm{Mg}$, magnesium; Fe, iron; UIBC, unsaturated iron binding capacity; UA, uric acid; Glu, glucose.

old children. These increased GGT levels, caused by enhanced transcriptional regulation of GGT genes in fetal liver, progressively decrease and maintain low levels for up to 18 years of age. ${ }^{21,22}$ GGT is a microsomal enzyme that catalyzes the hydrolysis of extracellular glutathione. Glutathione is essential for antioxidant defense in the lung and is found in epithelial lining fluid in 140-fold higher levels compared to in plasma, suggesting that GGT may be an indicator or predictor of diseases involving oxidative stress. ${ }^{23}$ Oxidative stress is unavoidable in preterm and even in full-term infants, as normal transition from the intrauterine to extrauterine environment involves an abrupt increase in oxygen. ${ }^{24}$ In this study, ALT showed the narrowest and lowest reference interval compared to AST, ALP, and GGT. This suggests that ALT is a useful screening test for neonatal liver disease. On the other hand, because the reference range of $\mathrm{LDH}$ in neonates was too wide and the upper limit level of the range was higher than $900 \mathrm{U} / \mathrm{L}$ in this study, clinicians need to be careful in interpreting the results. Lipid profiles including total cholesterol, HDL-C, LDL-C, and triglycerides confirmed previous findings that neonates exhibit low levels of 
serum cholesterol and triglycerides at birth, which increase rapidly during the first week after birth. ${ }^{25,26}$ In addition, some parameters such as total bilirubin and phosphate showing increased and wider reference intervals in neonates may suggest variable organ development within a population or their immature homeostatic mechanisms. ${ }^{25}$

One of the limitations in our study is the fact that preterm neonates were comprised of a heterogeneous group ranging from extremely preterm (less than 28 gestational weeks) to moderate to late preterm ( 32 to 37 gestational weeks). The reference subjects used in the current study were considered to be in good health because all of their CRP concentrations were less than $0.05 \mathrm{mg} / \mathrm{dL}$ and all neonates were discharged without special problems. Nevertheless, it is difficult to demonstrate definitively that all newborns were truly free from underlying pathologies. The reference intervals could be affected if any of the included individuals were not truly diseasefree and healthy. Therefore, our results should be confirmed by a large-scale, well-designed multi-center study. In addition, given the exclusion criteria without considering the neonatal conditions after birth based on single tertiary center study, our study population may not represent the actual reference populations. In this study, we recruited only 79 neonates, which is less than the minimum number required of 120 according to CLSI guideline. ${ }^{3}$ So, we could not establish our own reference intervals for each analyte.

In conclusion, we compared the reference intervals for 23 biochemical tests in the cord blood of neonates in our hospital, and these data will be useful for clinical decision-making for the management of neonates.

\section{REFERENCES}

1. Concordet D, Geffre A, Braun JP, Trumel C. A new approach for the determination of reference intervals from hospital-based data. Clin Chim Acta 2009; 405: 43-48.

2. Melioli G, Risso FM, Sannia A, et al. Reference values of blood cell counts in the first days of life. Front Biosci (Elite Ed) 2011; 3: 871-878.
3. Horowitz GL, Altaie S, Boyd JC, et al. EP28-A3c: Defining, establishing, and verifying reference intervals in the clinical laboratory; Approved guideline. (3rd ed). Wayne, PA: Clinical and Laboratory Standards Institute; 2010.

4. Alström T, Gräsbeck R, Lindblad B, Solberg HE, Winkel P, Viinikka L. Establishing reference values from adults: recommendation on procedures for the preparation of individuals, collection of blood, and handling and storage of specimens. Committee on Reference Values of the Scandinavian Society for Clinical Chemistry. Scand J Clin Lab Invest 1993; 53: 649-652.

5. Solberg HE, Gräsbeck R. Reference values. Adv Clin Chem 1989; 27: 1-79.

6. Schnabl K, Chan MK, Gong Y, Adeli K. Closing the gaps in paediatric reference intervals: the CALIPER initiative. Clin Biochem Rev 2008; 29: 89-96.

7. Jones G, Barker A. Reference intervals. Clin Biochem Rev 2008; 29(Suppl 1): S93-S97.

8. Siest G. Study of reference values and biological variation: a necessity and a model for Preventive Medicine Centers. Clin Chem Lab Med 2004; 42: 810-816.

9. Cho SM, Lee SG, Kim HS, Kim JH. Establishing pediatric reference intervals for 13 biochemical analytes derived from normal subjects in a pediatric endocrinology clinic in Korea. Clin Biochem 2014; 47: 268-271.

10. Aytekin M, Emerk K. Accurate reference intervals are required for accurate diagnosis and monitoring of patients. EJIFCC 2008; 19: 137-141.

11. Reed AH, Henry RJ, Mason WB. Influence of statistical method used on the resulting estimate of normal range. Clin Chem 1971; 17: 275-284.

12. Sinton TJ, Cowley DM, Bryant SJ. Reference intervals for calcium, phosphate, and alkaline phosphatase as derived on the basis of multichannel-analyzer profiles. Clin Chem 1986; 32(1 Pt 1): 76-79.

13. Lahti A. Partitioning biochemical reference data into subgroups: comparison of existing methods. Clin Chem Lab Med 2004; 42: 725-733.

14. Harris EK, Boyd JC. On dividing reference data into subgroups to produce separate reference ranges. Clin Chem 1990; 36: 265-270.

15. Ceriotti F. Establishing pediatric reference intervals: a challenging task. Clin Chem 2012; 58: 808-810.

16. Christensen RD, Henry E, Jopling J, Wiedmeier SE. The CBC: reference ranges for neonates. Semin Perinatol 2009; 33: 3-11. 
17. Perkins SL, Livesey JF, Belcher J. Reference intervals for 21 clinical chemistry analytes in arterial and venous umbilical cord blood. Clin Chem 1993; 39: 1041-1044.

18. Rao R, Georgieff MK. Iron in fetal and neonatal nutrition. Semin Fetal Neonatal Med 2007; 12: 54-63.

19. Lee HR, Shin S, Yoon JH, Roh EY, Chang JY. Reference intervals of hematology and clinical chemistry analytes for 1-year-old Korean children. Ann Lab Med 2016; 36: 481-488

20. Orakzai SA, Siddiqui KA, Ayub M, Saeed AK. Serum proteins in infants. J Pak Med Assoc 1987; 37: 251255.

21. Heiduk M, Page I, Kliem C, Abicht K, Klein G. Pediatric reference intervals determined in ambulatory and hospitalized children and juveniles. Clin Chim Acta 2009; 406: 156-161.
22. Fierabracci V, Franzini $M$, Baggiani $A$, et al Developmental variations of plasma gammaglutamyltransferase fractions in humans and in laboratory mammalians. Biomarkers 2012; 17: 43-47.

23. Whitfield JB. Gamma glutamyl transferase. Crit Rev Clin Lab Sci 2001; 38: 263-355.

24. Kim DB, Lim G, Oh KW. Determination of reference range of gamma glutamyl transferase in the neonatal intensive care unit. J Matern Fetal Neonatal Med 2017; 30: 670-672.

25. Dolphin PJ, Breckenridge WC, Dolphin MA, Tan $\mathrm{MH}$. The lipoproteins of human umbilical cord blood apolipoprotein and lipid levels. Atherosclerosis 1984; 51: 109-122.

26. Colantonio DA, Kyriakopoulou L, Chan MK, et al Closing the gaps in pediatric laboratory reference intervals: a CALIPER database of 40 biochemical markers in a healthy and multiethnic population of children. Clin Chem 2012; 58: 854-868. 